\title{
Emigration of juvenile banana prawns Penaeus merguiensis from a mangrove estuary and recruitment to offshore areas in the wet-dry tropics of the Gulf of Carpentaria, Australia
}

\author{
D. J. Staples \& D. J. Vance \\ Division of Fisheries Research, CSIRO Marine Laboratories, P. O. Box 120, Cleveland, Queensland 4163, Australia
}

\begin{abstract}
Four yr sampling (1975 to 79) of emigrating juvenile Penaeus merguiensis at the mouth of the Norman River estuary in the southeastern Gulf of Carpentaria clearly demonstrated the importance of rainfall to the emigration processes of this penaeid prawn. Most emigration occurred during the wet summer months (Dec to Mar) when $80 \%$ of annual precipitation occurred. The majority of prawns were caught within $0.5 \mathrm{~m}$ of the water surface across the width of the estuary. Marked tidal and diel rhythms in emigration were observed, the two interacting to give different patterns of emigration depending on whether the hours of darkness coincided with the ebb tide. Emigration was extremely variable over short time scales (weeks) and was affected by the rainfall of the previous 3 wk, the number of resident juvenile prawns and the phase of the neap/spring cycle. When results were pooled over longer time scales (months and years), the effects of tide phase and juvenile population numbers became less important. Rainfall alone accounted for over $70 \%$ of the observed variation in monthly emigration rate. The size at which prawns emigrated also depended on rainfall and estuarine salinity and was inversely related to the number of emigrants. In wet years, a large number of prawns of all sizes emigrated, whereas in dry years, only a few larger prawns migrated. Recruitment to the offshore fishery occurred approximately $8 \mathrm{wk}$ after the prawns left the estuary. Over the $4 \mathrm{yr}$ of study, the inter-annual differences in rainfall and prawn emigration from the Norman River were reflected in the commercial catch of $P$. merguiensis in the southeastern Gulf.
\end{abstract}

\section{INTRODUCTION}

The banana prawn Penaeus merguiensis in the southeastern Gulf of Carpentaria has 2 main periods of increased spawning activity each year: a large peak in the population fecundity in March-April (autumn) and a much smaller peak in September-October (spring) (Crocos \& Kerr 1983). However, seasonal changes in larval advection from the offshore spawning areas result in a much higher proportion of larvae reaching the estuarine nursery areas in spring than in autumn (Rothlisberg et al. 1983). This spring generation enters the mangrove areas as postlarvae with a peak in abundance in the Norman River occurring often in November (Staples \& Vance 1985). After 1 to $3 \mathrm{mo}$, juvenile prawns emigrate from the estuary during the wet season (Dec to Mar) (Munro 1975, Staples 1980). Recruitment of $P$. merguiensis into the offshore fishery therefore only occurs during a short period (Jan to Apr) each year and is composed mainly of prawns originating from the spring spawning.

This paper is the second in a series examining the causal mechanisms of the large fluctuations observed in the commercial yield of Penaeus merguiensis in the Gulf of Carpentaria. In the first paper (Staples \& Vance 1985), which was based on 4 yr of sampling of postlarvae in the Norman River, we examined the factors influencing the immigration of postlarvae into the nursery estuary. The year-to-year variation in the spring immigration of postlarvae was associated with both the amount of rainfall recorded during the previous wet season and the relative abundance of spawning females. The resulting year-to-year differences in the number of juvenile prawns in the estuary, however, were not directly reflected in the subsequent offshore catch of P. merguiensis (Hynd 1974, Vance et al. 1985). 
Events that affect whether juvenile prawns migrate back offshore from the nursery areas appear to be more decisive in determining the abundance of adult prawns and require further study.

In general, penaeid prawns have been found to emigrate from inshore nursery areas only during the ebb tide, with more prawns moving at night than during the day (Idyll et al. 1964, Yokel et al. 1969, Garcia 1977). Catches of emigrants are also usually higher at new and full moon (Copeland 1965, Subrahmanyam 1967, Yokel et al. 1969, Garcia 1977). Racek (1959) and more recently, Boddeke et al. (1977) argue that migration is linked to moulting periodicity, and because moulting occurs around full moon, migration is inhibited until after the last quarter. Many other environmental factors are known to stimulate the offshore migration of prawns. In areas where the seasonal range of temperature is small but rainfall is very seasonal, such as in India, Madagscar, Ivory Coast and northern Australia, rainfall appears to be a driving force (Garcia \& LeReste 1981). In areas where temperature fluctuations are more seasonal, for example Florida, Texas and Senegal, temperature changes play a more dominant role. The size of emigrating prawns also follows a seasonal cycle, which in the case of the banana prawn. means that smaller prawns migrate during the wet season, when emigration is at its maximum (Staples 1980).

Studies on the emigration of Penaeus merguiensis have included those of Munro (1975), Chong (1979) and Staples (1980). Both Munro and Staples found that rainfall stimulated the emigration of juvenile prawns from the estuaries in the southeastern Gulf of Carpen- taria. Because this region experiences a very restricted wet season each year, emigration of prawns is also seasonal. In the Straits of Malacca, where rainfall is more continuous, juvenile prawn emigration was also found to be more protracted, although recruitment into the offshore fishery was higher following increased rainfall in October-November (Chong 1979). Rainfall is positively correlated with prawn catches in the southern Gulf of Carpentaria; catches can be predicted using rainfall data collected during the wet season before commercial fishing commences (Vance et al. 1985). The basic pattern of juvenile prawn emigration from the Norman River has been described by Staples (1980). In the present paper we present further data on the emigration of juveniles from the same river (based on sampling from 1975 to 1979), and examine the factors affecting both the number and size of emigrating $P$. merguiensis over a range of time scales.

\section{MATERIALS AND METHODS}

Prawns emigrating from the Norman River estuary were sampled with nets of $2 \mathrm{~mm}$ mesh suspended from buoys set across the river about $2 \mathrm{~km}$ from the mouth (Fig 1a). The river at this point is $600 \mathrm{~m}$ wide and $6 \mathrm{~m}$ deep in the mid-channel. Nets set on the surface measured $1.0 \mathrm{~m}$ by $0.5 \mathrm{~m}$. Smaller nets $(0.5 \mathrm{~m}$ by $0.5 \mathrm{~m})$ were used in depths greater than $1 \mathrm{~m}$ because of the physical difficulty of lifting the larger net in a fast current (up to $200 \mathrm{~cm} \mathrm{~s}^{-1}$ ). A test of the catch rates of the 2 types of nets showed a difference of only $1.6 \%$ between nets $(n=309$ for the large and $n=314$ for

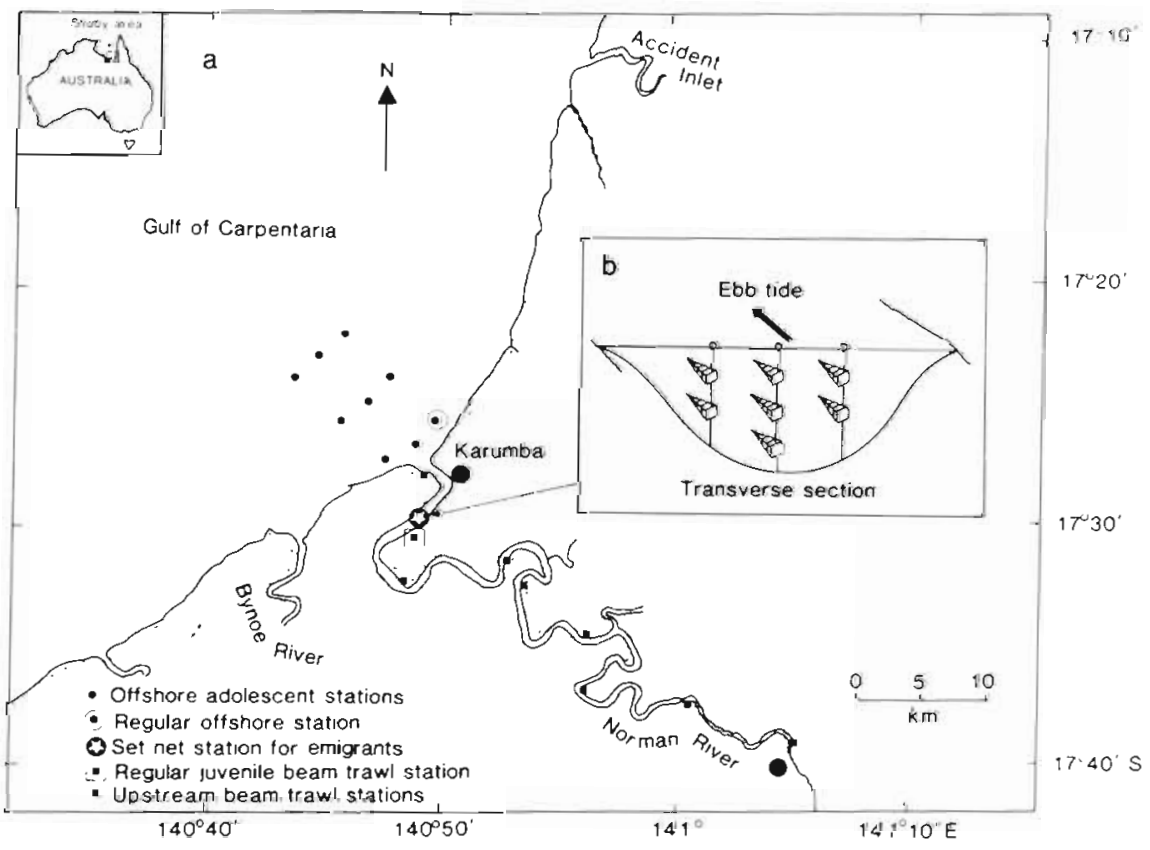

Fig. 1 (a) Study area in the southeastern Gulf of Carpentaria showing sites sampled for resident juvenile, emigrating and adolescent Penaeus merguiensis. (b) Array of set nets used to examine the spatial distribution of emigrating prawns 
2 small nets). The spatial distribution of emigrating prawns was estimated on 13 occasions following rain by setting an array of 7 nets at 3 depths $(0,3$, and $5 \mathrm{~m})$ at the mid-channel location and 2 depths $(0$ and $3 \mathrm{~m})$ at the other 2 stations (Fig. 1b). The depth distribution of prawns was further examined on 29 occasions with 3 nets at the mid-channel location.

The temporal distribution of emigrants was also examined over several time scales using the surface net of the mid-channel location. Except during 1977-1978, when the net was set more frequently, the net was set twice weekly during the wet season (Dec to Mar) to coincide with changes in both the neap-spring tidal phase cycle and the lunar phase cycle (tidal and lunar changes are not in phase in this region of the Gulf of Carpentaria). In early 1977 the nets were set and lifted every $4 \mathrm{~h}$ throughout $4 \mathrm{ebb}$ tides to examine the tidal and diel cycles of emigration. Day-to-day variability in emigration was examined between December 1977 and March 1978 by setting nets every second day. Lunar and tidal phase cycles were examined by time series analyses (Chatfield 1975).

The relative abundance of juveniles in the Norman River was assessed from weekly sampling with a rectangular beam trawl $(1.0 \mathrm{~m} \times 0.5 \mathrm{~m})$ fitted with a $2 \mathrm{~mm}$ mesh net and a $1 \mathrm{~mm}$ mesh cod-end as described by Staples \& Vance (1985). Samples were taken at low tide from a fixed station close to the area of emigrant sampling (Fig. 1a). An upstream transect was sampled every $3 \mathrm{wk}$ on alternate spring and neap tides to provide information on the upstream distribution of prawns. The relative abundance of juveniles was then estimated as the product of abundance (no $\mathrm{m}^{-2}$ trawled) at the estuary mouth and the proportion of the total range in the prawn's distribution occupied on the day of sampling

Adolescent prawns just offshore from the Norman River mouth were sampled weekly during the wet season using a $3.0 \mathrm{~m}$ head rope net $(1.3 \mathrm{~cm}$ mesh fitted with a $2 \mathrm{~mm}$ mesh cod-end) attached either to a pair of otter boards or to a fixed beam trawl frame. Trawls were made along a sandy beach adjacent to the river estuary (Fig. 1a) in less than $1.0 \mathrm{~m}$ of water on the flooding tide. On 3 occasions during the study, a grid of 9 stations extending $10 \mathrm{~km}$ from the shore was trawled to determine changes in the distribution and size of prawns during their offshore migration. Further offshore, size composition of samples obtained from the commercial catch were kindly made available by $\mathrm{Mr} \mathrm{I}$. Somers of the CSIRO Marine Laboratories, Cleveland, Australia.

All prawns caught were identified to species and the carapace length of Penaeus merguiensis was measured to the nearest $0.1 \mathrm{~mm}$ with an ocular micrometer for prawns less than $4 \mathrm{~mm}$ carapace length and with calipers for larger prawns. Rainfall, water temperature and salinity data were collected, as described by Staples (1983). Relations between $P$. merguiensis emigration, environmental variables, and the relative abundance and median carapace length of the juvenile population were examined using standard correlation matrices and multiple regression techniques (Draper \& Smith 1966).

\section{RESULTS}

\section{Environment and seasonality}

Environmental conditions over the study period have been described in detail by Staples (1983) and Staples \& Vance (1985). Both rainfall and temperature show distinct seasonal cycles at the study site. The Gulf region is characterized by a cool southeasterly trade wind from April to November and a warmer northwesterly monsoonal period from December to March, during which time over $80 \%$ of the annual rainfall is precipitated. The mean annual rainfall over the past $10 \mathrm{yr}$ was $1114 \mathrm{~mm}$. Both the number and size of juvenile prawns emigrating from the Norman River
Fig. 2. Penaeus merguiensis. Seasonal cycle of emigration (solid histogram), rainfall (shaded histogram) and mean carapace length (solid line \pm SE bars) of juveniles from the Norman River for 1975 to 1979

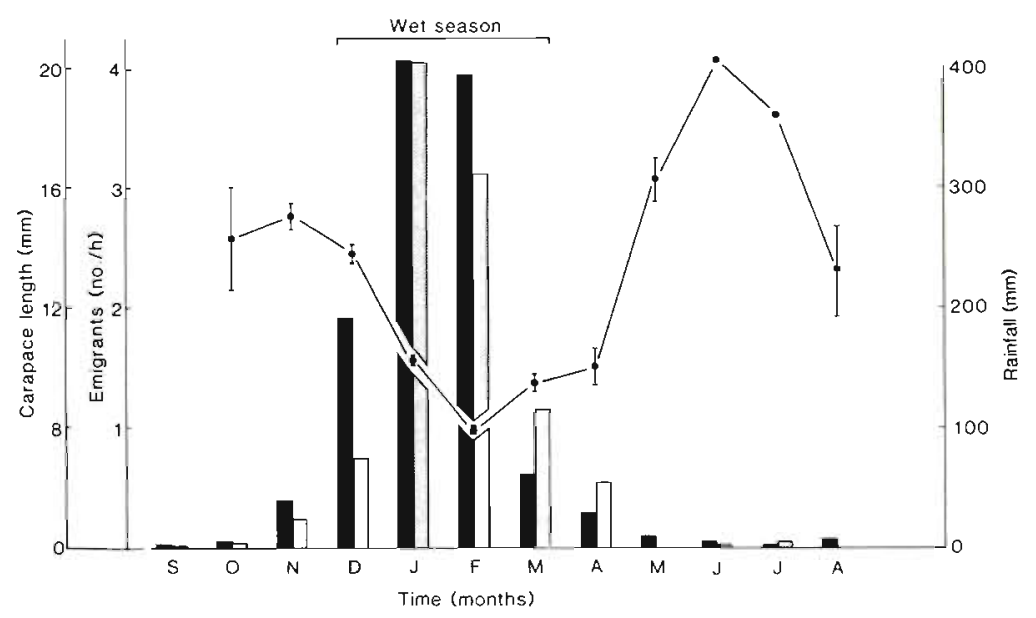


over the 4 yr of study also displayed marked seasonal periodicity (Fig. 2), with prawn emigration largely confined to the wet season. The mean size of emigrants pooled over all years ranged from $7.9 \pm 0.1 \mathrm{~mm}$ in February to $17.2 \pm 0.7 \mathrm{~mm}$ in May (Fig. 2). Mean size

a

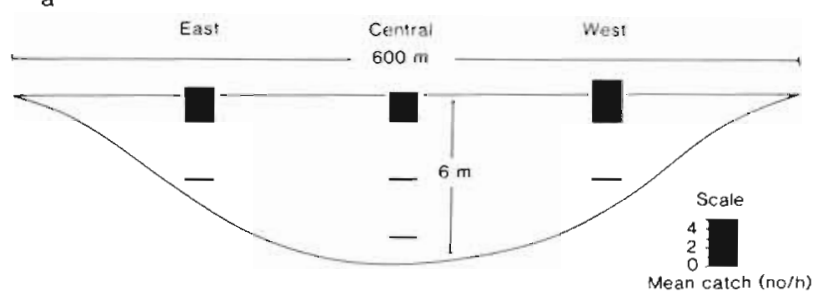

b

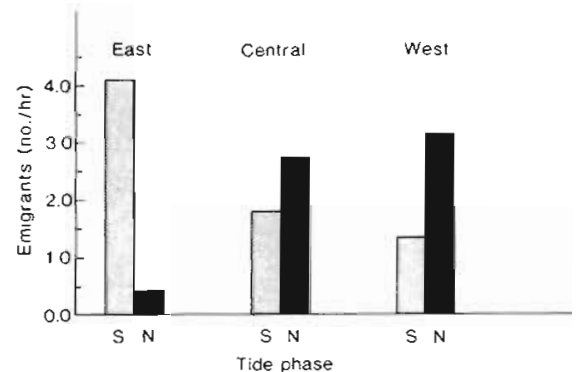

Fig. 3. Penaeus merguiensis. (a) Mean depth and lateral distribution of emigrating juveniles taken with an array of 7 set nets near the Norman River estuary mouth. (b) Changes in the lateral distribution of emigrating juveniles during spring (S) and neap (N) tides

was inversely correlated with emigration rate $(\mathrm{r}=$ -0.694 , d.f. $=11, P<0.01$ ), i.e. a large number of small prawns migrated during the wet season but only a small number of larger prawns migrated during the dry season. Analyses in the following sections relate mainly to the wet season emigration.

\section{Depth and lateral distribution of emigrating prawns}

Depth distribution

When the full array of 7 nets was used, the majority of prawns were caught in the surface nets (Fig. 3a) Over $80 \%$ of the prawns were also taken in the surface net on 29 other occasions when 3 depth strata were sampled at the mid-river location. An analysis of variance was carried out on the ratio of prawns caught at each depth (after arc sine transformation) to determine the effects of tide and moon on the depth distribution. Tide phase was estimated from observed tidal ranges, while moon phase changes were simulated using both sine and cosine curves with a period of $29.53 \mathrm{~d}$. Tide phase had no significant effect $(P>0.05)$. Moon phase was significant at the $5 \%$ level $(F=3.62$, d.f. $=2,32$, $\mathrm{P}<0.05$ ); more prawns were at deeper levels just prior to the new moon. The sizes of prawns caught in the 3 depth strata were not significantly different $(P>0.05)$.

\section{Lateral distribution}

The combined results from the 13 occasions when the full array of 7 nets was used showed no apparent differences in the lateral distribution across the river (Fig. 3a). Analysis of variance, however, suggested an interaction of location and tide phase, with more prawns caught near the eastern bank during spring tides and fewer during neap tides (Fig. 3b). Approximately $40 \%$ of the observed variation in the proportion of catch in either the western or eastern location was related to tide height $(\mathrm{r}=0.663$, d.f. $=12 ; \mathrm{P}<0.01)$ and the effect was significant for the eastern location $(F=7.51$, d.f. $=1.9, P<0.05)$. Moon phase had no
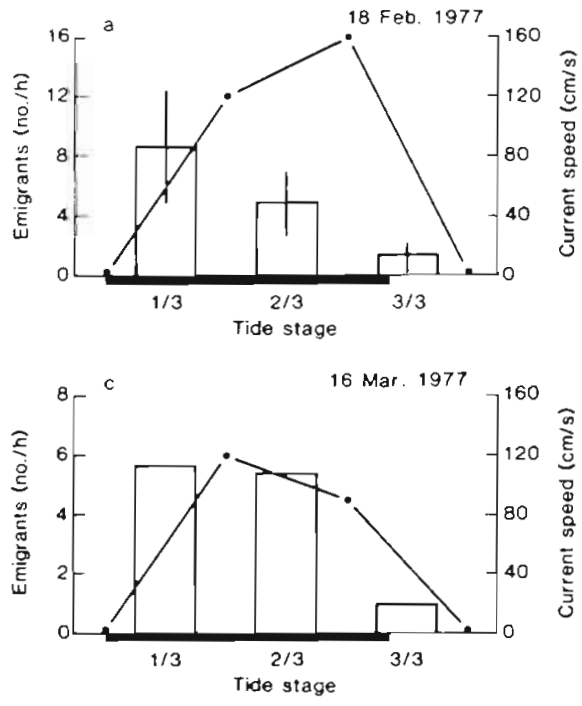
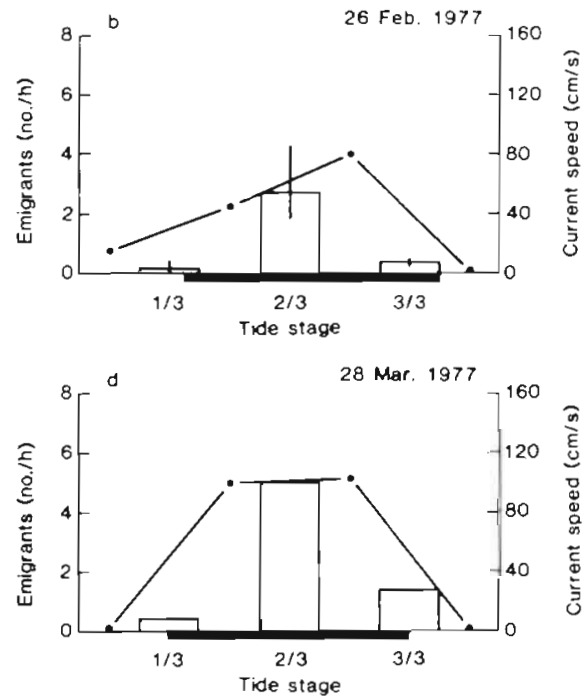

Fig. 4. Penaeus merguiensis. Current speed (solid line) and prawn emigration rate (histogram \pm range observed over 3 locations across the width of the river) over the ebb tide period on 4 dates during $\mathrm{Feb}$ and Mar 1977 Dark bars indicate hours of darkness 
apparent effect. The size of prawns caught in these locations was also dependent on tide (eastern location, $\mathrm{F}=22.12$, d.f. $=1,9, \mathrm{P}<0.01$ and western location, $\mathrm{F}$ $=7.07$, d.f. $=1,9, \mathrm{P}<0.05$ ), with increased catches always associated with a decrease in the size of prawns.

\section{Short-term influences}

Tidal and diel cycles

Emigration rate. Tides in the Norman River are essentially diurnal, although semi-diurnal tides can occur during the neap tide period (Staples 1983). On the few occasions when one semi-diurnal ebb tide occurred exclusively at night and the other occurred during the day, the preference of the prawns for night emigration could be clearly demonstrated. For example, on 23 March 1977, the mean emigration rate during the night ebb tide was 1.10 prawns $\mathrm{h}^{-1}$, whereas during the following day the rate was only 0.14 prawns $\mathrm{h}^{-1}$. More typically, the ebb tide period extended for approximately $12 \mathrm{~h}$, with part at night and part during the day. When the period of darkness fell evenly within the ebb tide period (e.g. Fig. 4 b, d), the distribution of emigration was symmetrical, with a maximum occurring during the middle of the ebb tide period at the time of maximum current speeds. When the ebb tide began after dusk (e.g. Fig. 4a, c) more prawns migrated earlier in the tidal cycle, resulting in a skewed distribution of emigration.

Size of emigrants. Changes in the mean size of emigrating prawns also occurred over the tidal cycle (Table 1). In both the symmetrical and asymmetrical

Table 1 Penaeus merguiensis. Changes in size of emigrating juveniles (CL: mean carapace length; SE: standard error; $\mathrm{n}$ : number sampled) throughout three $4 \mathrm{~h}$ tide stages of the ebb tide

\begin{tabular}{|c|c|c|c|c|c|c|c|c|c|}
\hline \multirow{3}{*}{$\begin{array}{l}\text { Date } \\
1977\end{array}$} & \multicolumn{9}{|c|}{ Tide stage } \\
\hline & \multicolumn{3}{|c|}{1} & \multicolumn{3}{|c|}{2} & \multicolumn{3}{|c|}{3} \\
\hline & $\mathrm{CL}$ & $\mathrm{SE}$ & $\mathrm{n}$ & $\mathrm{CL}$ & $\mathrm{SE}$ & n & $C L$ & $\mathrm{SE}$ & $\mathrm{n}$ \\
\hline $\begin{array}{l}17 \mathrm{Feb} \\
16 \mathrm{Mar}\end{array}$ & 11.8 & 0.2 & 112 & 10.7 & 0.4 & 72 & 5.3 & 0.4 & 26 \\
\hline $\begin{array}{l}25 \mathrm{Feb} \\
28 \mathrm{Mar}\end{array}$ & 9.0 & 1.2 & 5 & 12.4 & 0.5 & 42 & 9.1 & 0.7 & 13 \\
\hline Grand mean & 11.7 & 0.2 & 117 & 11.3 & 0.3 & 114 & 6.7 & 0.5 & 39 \\
\hline
\end{tabular}

Fig. 5. Penaeus merguiensis. (a) Day-to-day variation in the emigration rate of juveniles from the Norman River, Oct 1977 to Mar 1978. Periods of full moon are shown and ar. rows indicate times of spring tides, larger arrows denoting springs of larger amplitude. Horizontal bars show periods of ebb tides when the time of moon set coincided with the time of high tide. (b) Spectral analysis of emigration rate data
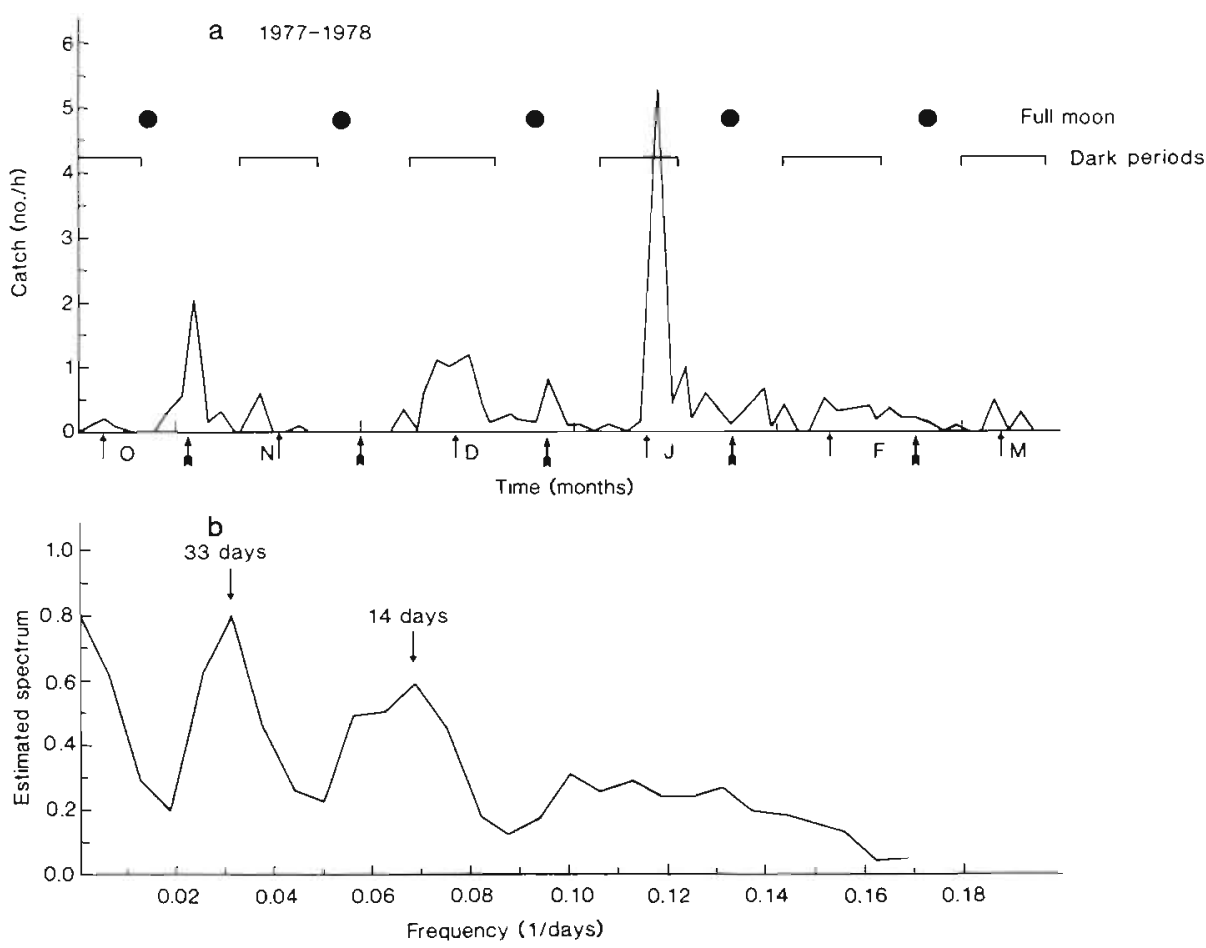
cases described in Fig 4, larger prawns occurred during times of higher emigration. Thus on 18 February and 16 March 1977, larger prawns occurred during the first stage of the tide, whereas on 25 February and 28 March, large prawns occurred during the middle stage.

Tidal and lunar phase cycles and environmental factors

Emigration rate. Because tides in the study area are dominated by the K1 (diurnal) harmonic, the tide phase is more closely related to the lunar sidereal month $(27.32 \mathrm{~d})$ than to the synodic month (29.53 d). The tide and moon phases, therefore, become progressively out of phase, coinciding only once a year. From October 1977 to March 1978, nets were used on the ebb tide every $2 \mathrm{~d}$ to determine whether emigration showed any systematic changes with either tide or lunar phases. Emigration during this period was extremely variable, with narrow peaks of emigration often associated with spring tides (Fig. 5a). Spectral analysis of the data shows 2 broad peaks in the frequencies, one corresponding to $14 \mathrm{~d}$ and the other to $33 \mathrm{~d}$ (Fig. 5b). Autocorrelation analysis gave similar results, with a peak at $14 \mathrm{~d}$ and a broad peak spanning 28 to $34 \mathrm{~d}$. These analyses indicate that tidal and lunar periodicities are present in the data, but are not strong. In general, a higher emigration rate occurred during spring tides, with a possibility of a larger peak every second spring tide. Data collected during the other years of study showed a similar periodicity, with higher emigration occurring during spring tides, especially when associated with the time of new and first quarter of the moon (Fig. 6).

Many other factors clearly affect the emigration rate. As well as tide phase (recorded as the tide range in metres) and moon phase (simplified sine curve), the effects of rainfall (measured at the mouth of the estuary and $50 \mathrm{~km}$ inland), salinity and water temperature (measured at the mouth of the estuary), juvenile prawn numbers (residents at time of migration), juvenile prawn size and the proportion of the ebb tide that occurred during darkness were also investigated, using multiple regression techniques. Emigration rate and juvenile abundance data were transformed by the 4 th root before analysis to satisfy assumptions of normality inherent in the technique. The inter-dependence of all variables was also closely checked throughout analyses to prevent confounding effects of related variables.

Rainfall, resident juvenile prawn numbers and tide range all significantly affected emigration rates: together they explained $33 \%$ of the observed variation

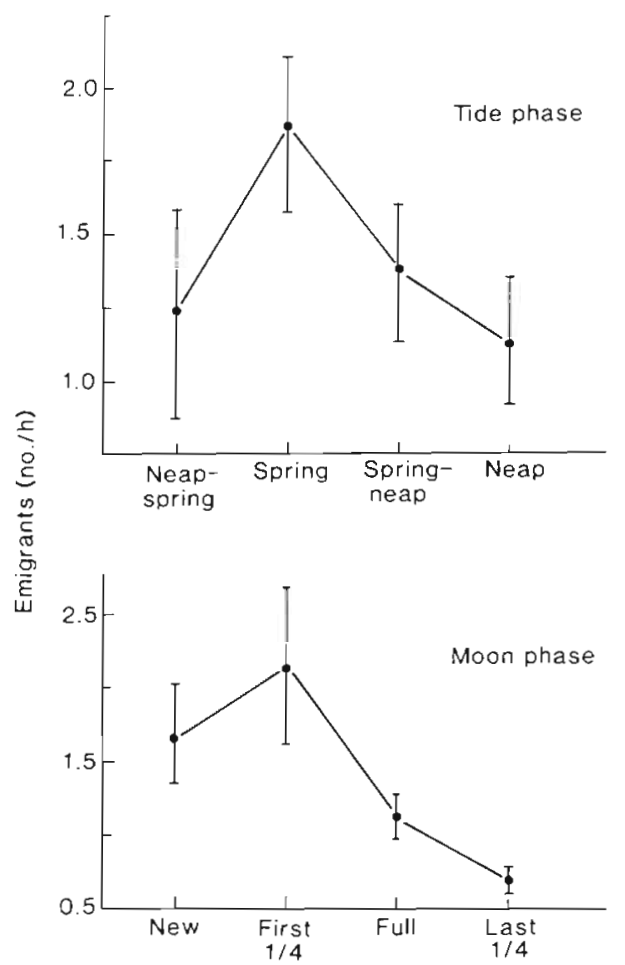

Fig. 6. Pendeus merguiensis. Emigration rate with (a) tide phase and (b) moon phase, over the 4 yr of study 1975-1979.

Vertical bars indicate \pm standard error of the mean

Table 2. Penaeus merguiensis. Forward multiple regression analysis of juvenile emigration with rainfall, juvenile prawn abundance and tide range for all sampling during the monsoon periods from Nov 1975 to Apr 1979 ( $\mathrm{n}=133$, R = multiple correlation coefficient, $\mathrm{r}==$ simple correlation coefficient)

\begin{tabular}{|c|c|c|c|c|}
\hline Variable & F value of variable & Multiple R & Simple $\mathrm{r}$ & Overall $F$ value \\
\hline Rainfall ${ }^{+}$ & $27.476^{\cdots}$ & 0.416 & 0.416 & $27.476^{\cdots}$ \\
\hline Juvenile numbers & $21.977 \cdots$ & 0.541 & 0.246 & $26.927^{\cdots}$ \\
\hline Tide range & $6.251^{\circ}$ & 0.571 & 0.265 & $20.759^{\cdots}$ \\
\hline \multicolumn{5}{|c|}{$\begin{array}{l}+ \text { Accumulated for } 3 \mathrm{wk} \text { prior to sampling date } \\
\because \mathrm{P}<0.01 \\
\cdot 0.01<\mathrm{P}<0.05\end{array}$} \\
\hline
\end{tabular}



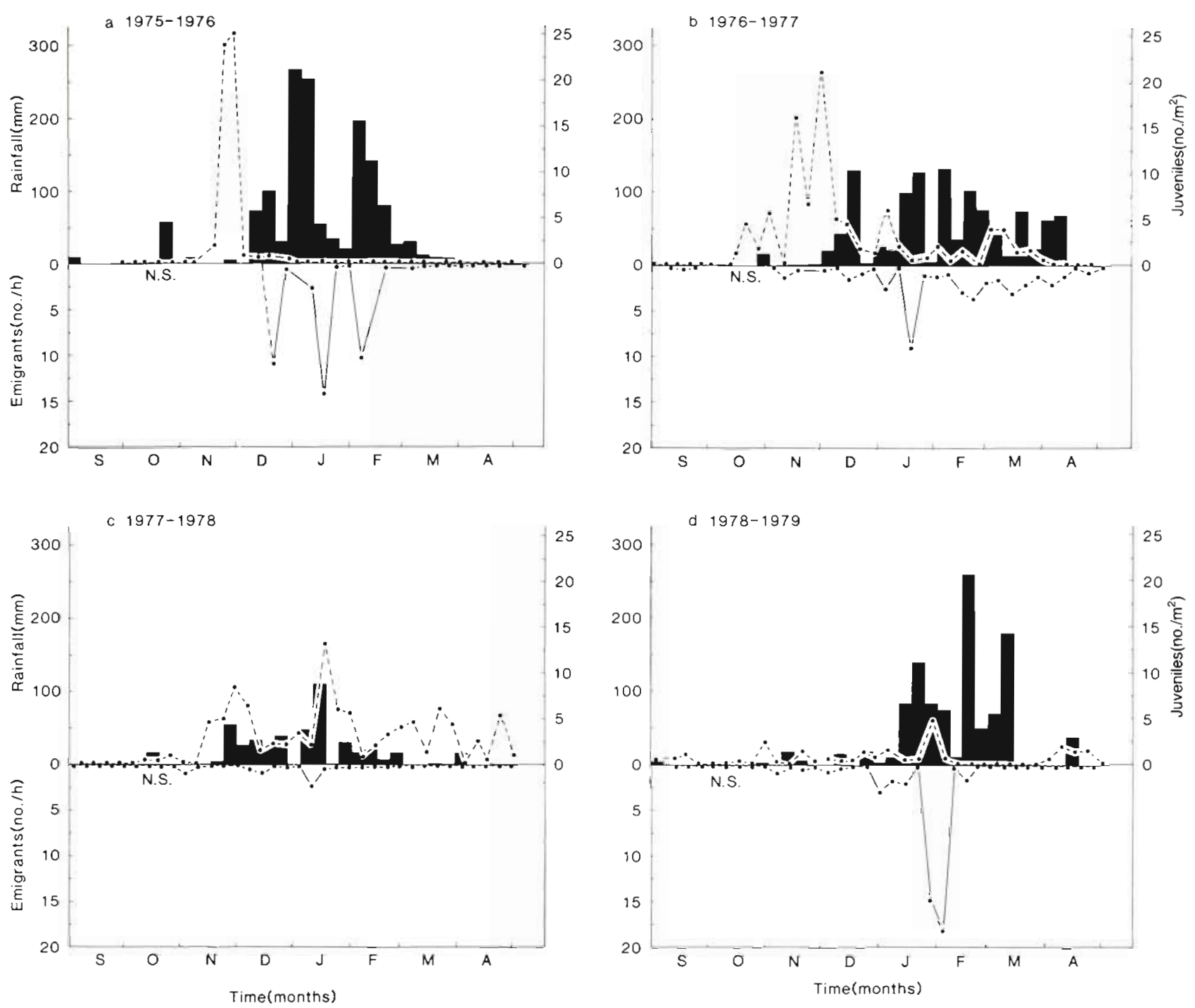

Fig. 7. Penaeus merguiensis. Weekly changes in rainfall (histogram), resident juvenile numbers (dashed line) and emigration rate (solid line) for (a) 1975-1976, (b) 1976-1977, (c) 1977-1978, and (d) 1978-1979

(Table 2, Fig. 7). Rainfall was accumulated over increasing time periods ranging from $1 \mathrm{~d}$ to $5 \mathrm{wk}$ before the time of emigration. Rainfall accumulated over 3 wk had the highest correlation. Rainfall at the mouth of the river and $50 \mathrm{~km}$ inland had similar effects. Rainfall differences by themselves accounted for only $17 \%$ of the day-to-day variation in emigration rate during the monsoonal period over 4 consecutive yr. The number of juveniles present in the river at the time of emigration was of particular importance during low population densities when, despite heavy rainfall, very little emigration could occur (e.g. Feb and Mar 1979: Fig. $7 \mathrm{~d}$ ). As in the time series analyses presented above, tide range was also shown to have a significant effect on emigration. The multiple regression analysis showed that moon phase did not contribute signifi- cantly to the explained variance; the apparent association between emigration and the new and first quarter moon seen in the raw data could be adequately explained by these other factors.

Size of emigrants. A similar analysis was carried out to determine whether the variation in the size of emigrating prawns could be related to the same factors Salinity changes and tide phase significantly affected emigrant size, accounting for $47 \%$ of the observed variance (Table 3, Fig. 8). Size of emigrants was positively correlated with salinity, such that the lower the salinity, the smaller the emigrants. When fresh water flowed down the river for several consecutive days, prawns of all sizes, including postlarvae (carapace length of $1 \mathrm{~mm}$ ), migrated from the river. During both 1977-1978 and 1978-1979 a small number of relatively 
Table 3. Penaeus merguiensis. Forward multiple regression analysis of the size of juvenile emigrants with salinity and tide range for all sampling dates during the monsoon periods from Nov 1975 to Apr 1979 ( $\mathrm{n}=97, \mathrm{R}=$ multiple correlation coefficient, $r=$ simple correlation coefficient)

\begin{tabular}{|lcccc|}
\hline Variable & $\begin{array}{c}\text { F value of } \\
\text { variable }\end{array}$ & $\begin{array}{c}\text { Multiple } \\
\mathrm{R}\end{array}$ & $\begin{array}{c}\text { Simple } \\
\mathrm{r}\end{array}$ & $\begin{array}{c}\text { Overal } \\
\text { Fvalue }\end{array}$ \\
\hline Salinity & $54.667 \cdots$ & 0.604 & 0.604 & $54.667 \cdots$ \\
Tide range & $17.838 \cdots$ & 0.683 & 0.522 & $41.097 \cdots$ \\
$\cdots \mathrm{P}<0.01$ & & & & \\
$\cdot 0.01<\mathrm{P}<0.05$ & & & \\
\hline
\end{tabular}

large prawns migrated from the estuary in OctoberNovember, and the size of emigrants then declined over the wet season. Sampling for emigrants in 1975-1976 and 1976-1977 did not start early enough in the year to determine the size of the OctoberNovember emigrants, although examination of the length frequency of resident juvenile prawns (Staples
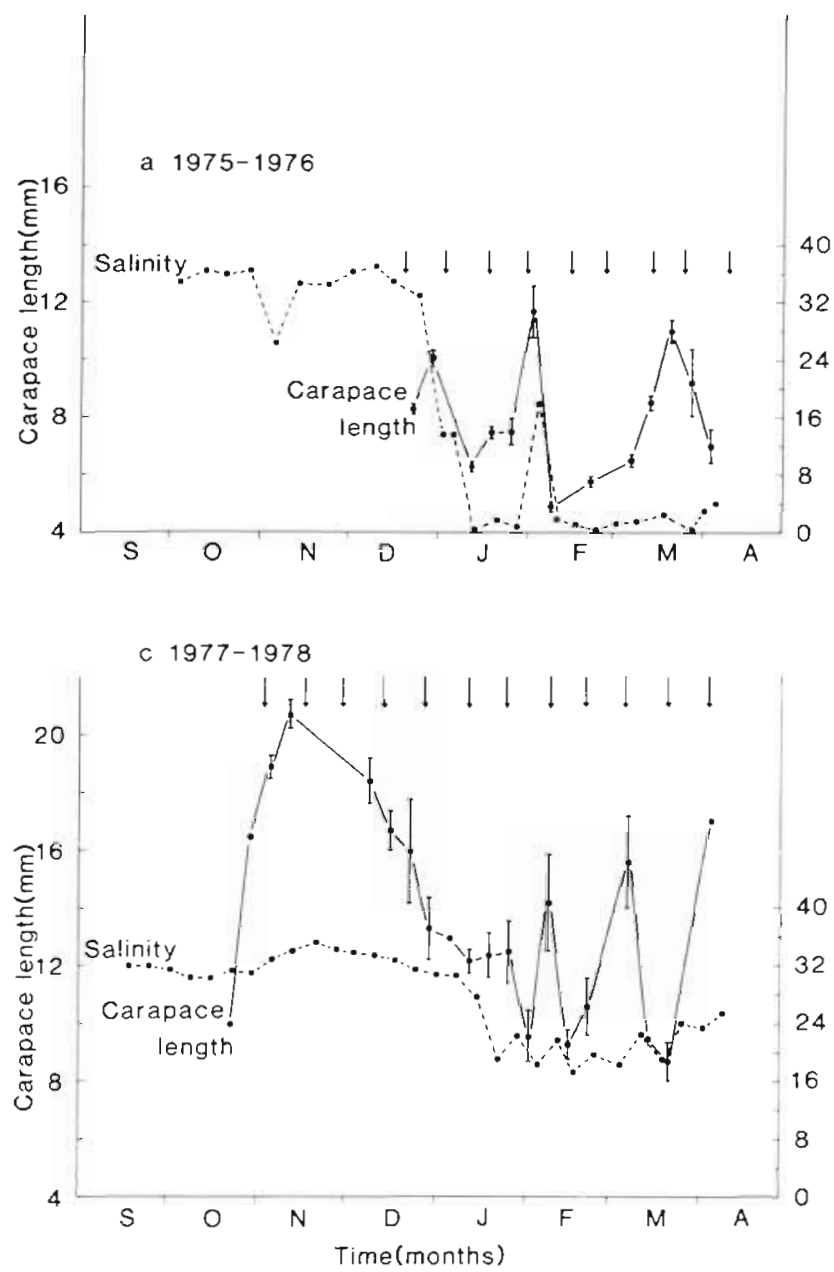

unpubl.) showed that a small number of large prawns left the estuary in October of these years. Throughout the wet season emigrant size fluctuated in response to salinity and tide phase changes

\section{Long-term influences}

\section{Effect of rainfall}

Emigration rate. Results pooled over monthly periods were much more predictable (Fig. 9) than the short-term data presented above. Approximately $74 \%$ of the variation observed in the number of prawns leaving the river each month could be explained by differences in rainfall of the same month $(x=0.859$, d.f. $=42, \mathrm{P}<0.01)$. For monsoonal months only, the correlation was still highly significant $(r=0.805$, d.f. $=20, \mathrm{P}<0.01)$. The degree of association between emigration and juvenile numbers varied considerably over the 4 yr of study, ranging from $\mathrm{r}=-0.022$, d.f. $=$
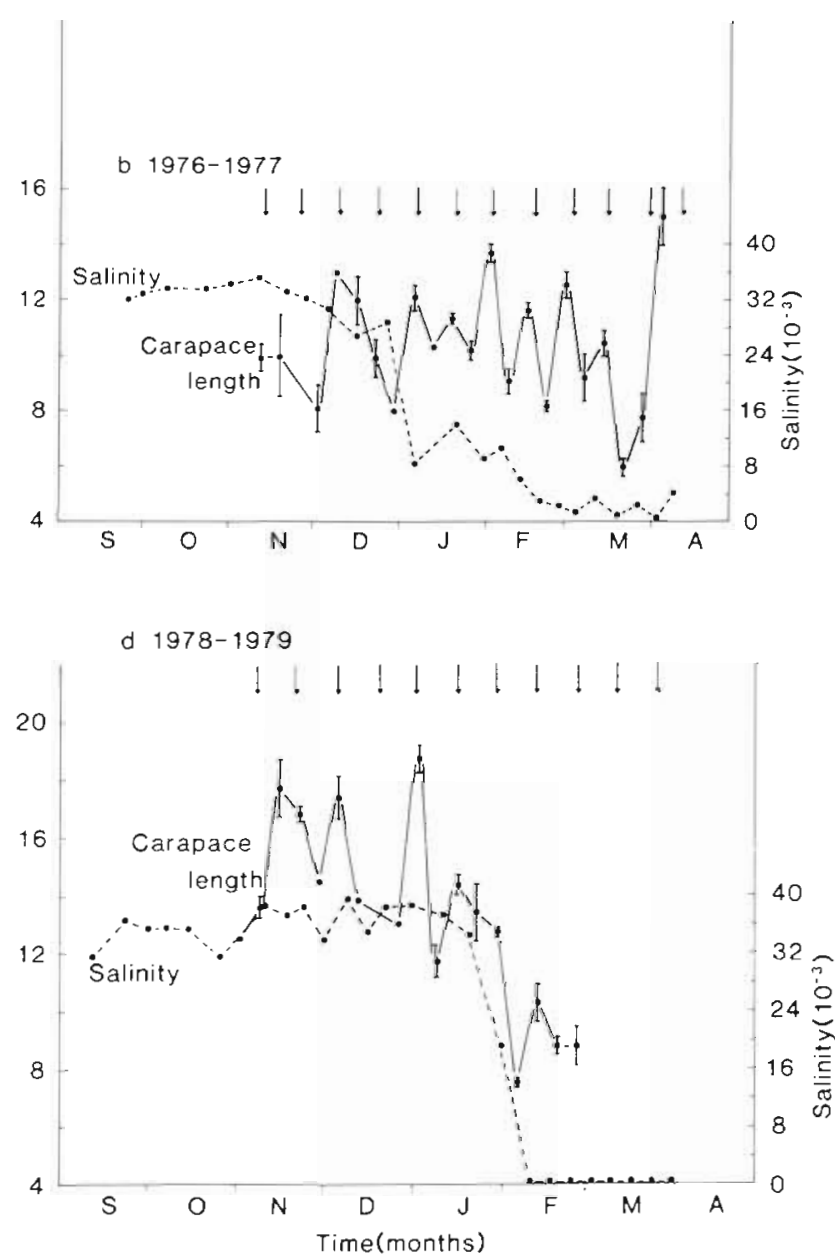

Fig. 8. Penaeus merguiensis. Weekly changes in the mean carapace length \pm SE (solid line with bars), salinity (dashed line) and spring tide phase (vertical arrow) for the periods (a) 1975-1976, (b) 1976-1977, (c) 1977-1978, and (d) 1978-1979 


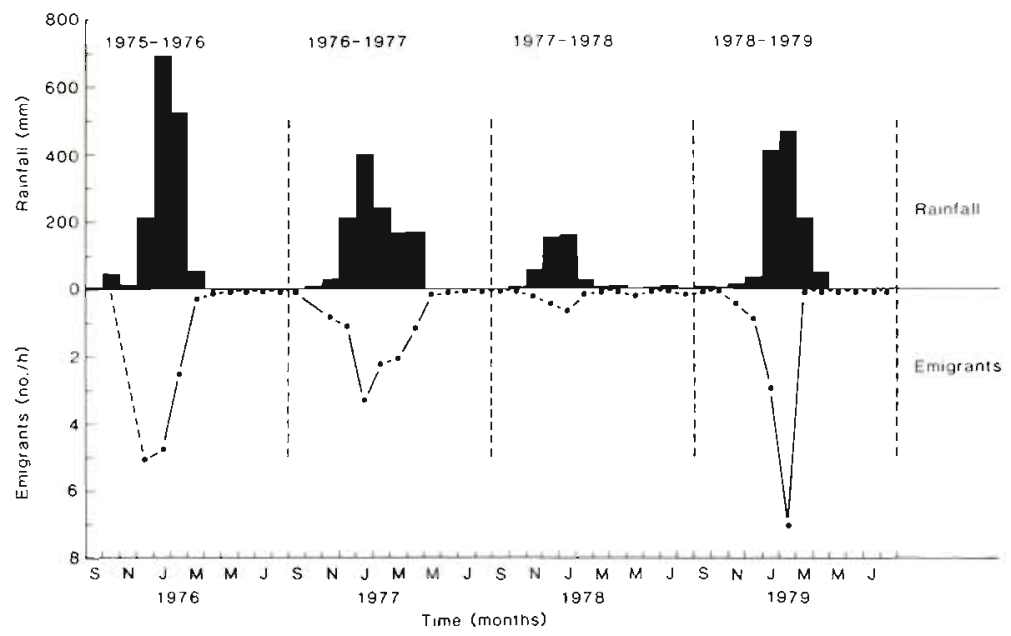

Fig. 9. Penaeus merguiensis. Changes in monthly rainfall (solid histogram) and mean monthly emigration rate of juvenile prawns from the Norman River Sep 1975 to Aug 1979
$11, \mathrm{P}>0.05$ in $1975-1976$ to $\mathrm{r}=0.629$, d.f. $=11, \mathrm{P}<$ 0.05 in 1977-1978. Taken over all months of sampling, however, neither the number nor size of juveniles present in the river at the time of rain added significantly to the explained variance. The result was the same when only wet season months were considered.

\section{Inter-annual variability}

Emigration rate. Year-to-year differences in relative strength of postlarval immigration, relative abundance
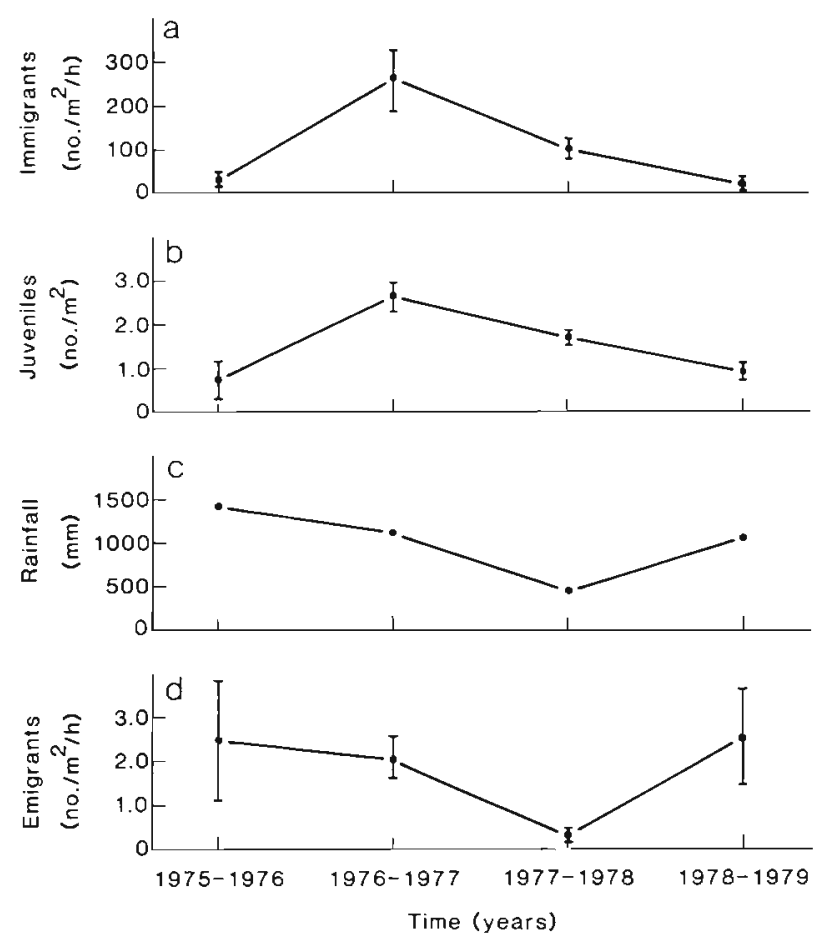

Fig. 10. Penaeus merguiensis. Indices of (a) spring postlarval immigration (b) spring juvenile prawn abundance (c) monsoonal rainfall, and (d) emigration of juveniles from the Norman River, 1975 to 1979 . Vertical bars give \pm SE of the means of juveniles, rainfall and emigration are compared in Fig. 10. Both immigration and emigration are expressed as the mean number of prawns caught per $h$ per $\mathrm{m}^{2}$ area of set nets. Postlarval data were taken from Staples \& Vance (1985). As shown for the monthly data, rainfall had most influence on emigration, with very little interaction effect of rainfall and either postlarvae or juvenile numbers. Thus in 1975-1976 and in 1978-1979, despite low juvenile numbers, both rainfall and emigration were high. In the dry year of 1977-1978, on the other hand, a relatively low proportion of the resident prawns actually emigrated. The ratio of the indices of emigration to immigration was 3.21 in $1978-1979$ and only 0.29 in 1977-1978. In 1976-1977, although postlarval immigration and juvenile numbers were high, rainfall and emigration were intermediate.

Size of emigrants. The mean annual carapace length of emigrants was inversely proportional to the number of emigrants and ranged from $6.9 \pm 0.1 \mathrm{~mm}(\mathrm{n}=773)$ in 1975-1976 (mean salinity $20.4 \times 10^{-3}$ ) to $12.9 \pm 0.3$ $\mathrm{mm}(\mathrm{n}=270)$ in 1977-1978 (mean salinity $28.5 \times$ $10^{-3}$ ) (Fig. 11). During the dry year of 1977-1978, when only the larger prawns emigrated, the difference between the mean size of emigrants and residents was $7.4 \mathrm{~mm}$. In the wetter year of 1975-1976, the difference was only $1.0 \mathrm{~mm}$. Differences for the other 2 yr were 5.5 $\mathrm{mm}$ and $3.1 \mathrm{~mm}$ for $1976-1977$ and 1978-1979, respectively.

\section{Recruitment to adult population}

Offshore migration

Over the 9 grid stations sampled offshore from the mouth of the Norman River, the density of prawns decreased and the size of prawns increased with increasing distance from the coast (Fig. 12). More prawns were also caught on the tidal flats adjacent to 

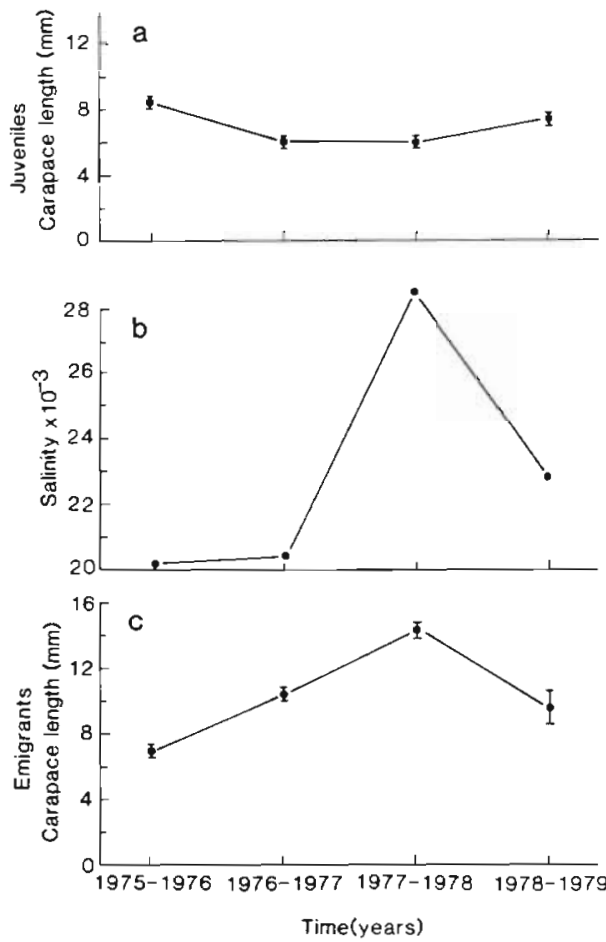

Fig. 11. Penaeus merguiensis. Mean carapace length of (a) resident juveniles and (c) emigrating juveniles shown together with (b) salinity of the Norman River from 1975 to 1979. Vertical bars denote \pm SE of the means

the main river channel than in the channel itself. The inshore station to the north of the river mouth was sampled regularly from January to March each year of study. In general, both the number and size of prawns caught at this station reflected changes in the number and size of prawns caught while moving out of the estuary (for prawn numbers $\mathrm{r}=0.46$, d.f. $=17, \mathrm{P}<$ 0.05 ; and for prawn size $\mathrm{r}=0.61$, d.f. $=17, \mathrm{P}<0.01)$.
The mean size of prawns caught at this inshore station over all years was $12.5 \pm 0.1 \mathrm{~mm}(\mathrm{n}=2374)$, which was $2.8 \mathrm{~mm}$ larger than the mean size of emigrants pooled over all years. The growth rate calculated by Staples (1980) is $1.2 \mathrm{~mm} \mathrm{wk}^{-1}$, indicating that after the prawns left the river, they stayed only briefly on the shallow flats before moving offshore.

When the length frequency of prawns caught in the offshore prawn fishery (Somers unpubl.) are compared with the pattern of emigration seen in the Norman River (lagged by $8 \mathrm{wk}$ ) the recruitment process of prawns into the offshore fishery can be followed (Fig. 13). In 1975-1976 (Fig. 13a), emigration of juveniles from the estuary was high in December and in the middle and end of January. The increase in the proportion of small prawns taken offshore reflected these pulses in emigration 8 wk after they had left the river (in the middle of February and the middle and end of March). In 1976-1977 (Fig. 13b), an enforced closure up to 15 March resulted in a large peak in the catch of commercial prawns in the last 2 wk of March. The mean size of prawns caught throughout this year's fishing season remained relatively constant, consistent with the steady rainfall and emigration of prawns from the river from December to March. In 1977-1978 (Fig. 13c) the rate of emigration of juveniles was low and the size of the offshore commercial catch was small. The size of prawns caught offshore increased steadily, reflecting the declining rate of emigration. In 1978-1979 (Fig. 13d) the large peak of emigration that occurred towards the end of January and early February resulted in late recruitment to the fishery and caused a marked reduction in the size of commercial prawns from the middle of March to the beginning of April. It is interesting to note that the bulk of the commercial yield of prawns consists of prawns that

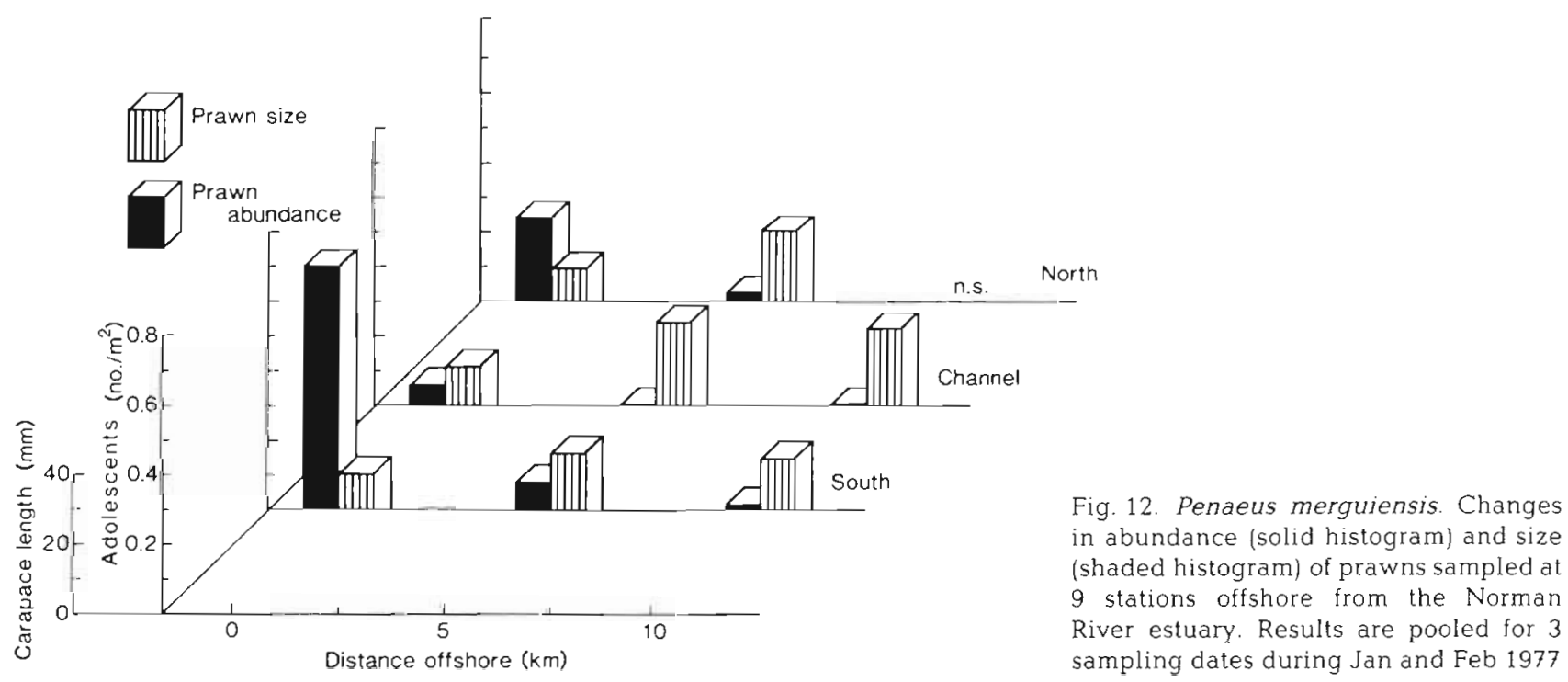



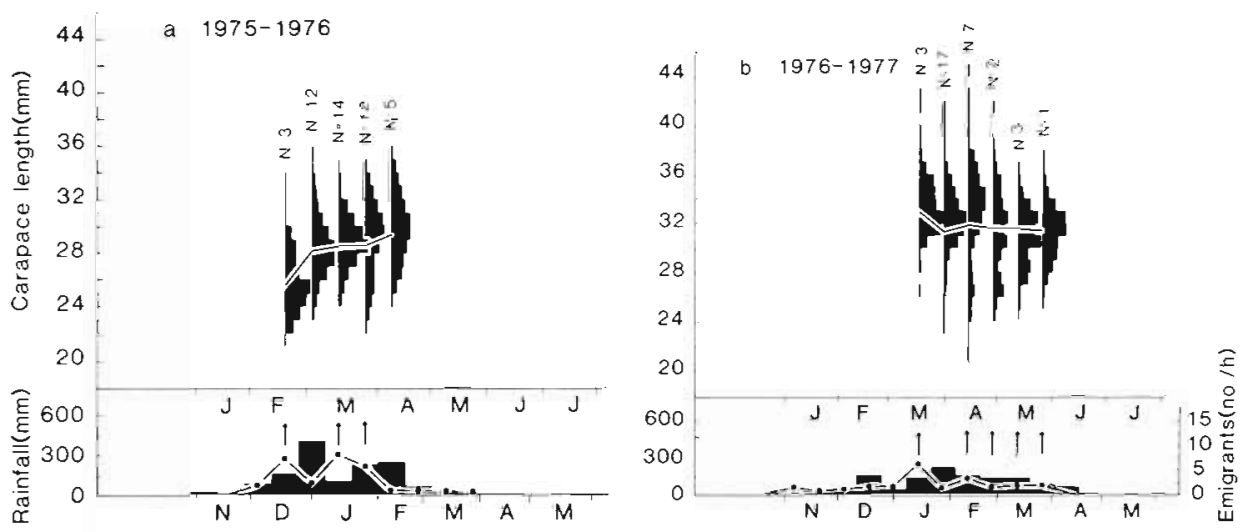

Fig. 13. Penaeus merguiensis. Relation between fortnightly juvenile emigration rate (solid line), rainfall (bottom histogram) and percentage length frequency of prawns in the offshore fishery (top histogram) Length frequencies have been displaced $8 \mathrm{wk}$ from the time of emigrant sampling. Solid line through histograms connects mean carapace lengths. Vertical arrows denote main times of juvenile prawn emigration. N: number of samples measured
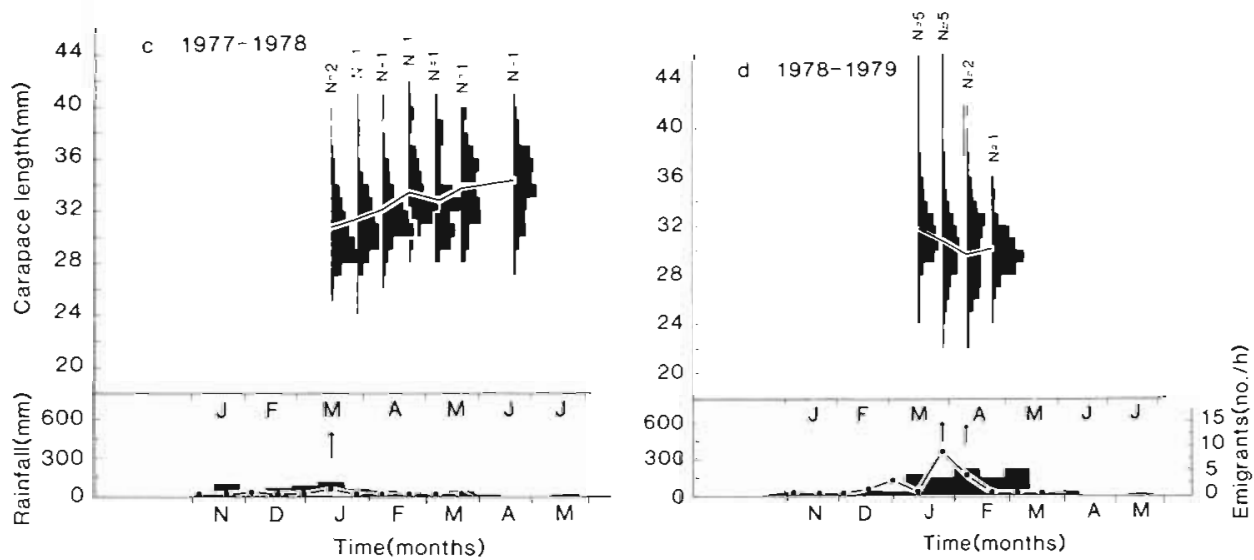

emigrated in December/January, while those that emigrated later in either February or March were not as well represented.

\section{Relation between emigration and offshore commercial catch}

Over the 13 yr of available data, the correlation between the commercial catch of Penaeus merguiensis and rainfall is 0.85 , d.f. $=12, \mathrm{P}<0.01$ (Fig. 14) Changes in the emigration rate (recorded in the pre- sent study as number of prawns per hour) were obviously reflected in the offshore catch, but were more closely related to rainfall. The biomass of emigrants, on the other hand, calculated from the mean weight and number of emigrants, was more accurately reflected in the subsequent catch. The difference in these 2 indices is most marked in 1976 when, despite a high rainfall and large number of emigrants, their mean size was small and the weight of the commercial catch was also less than would be expected on the basis of rainfall alone. An open season resulting in a large number of small prawns being taken early in the
Fig. 14. Penaeus merguiensis. Inter-annual variation in the commercial catch of (solid line) and rainfall (dashed line) in the southeastern Gulf of Carpentaria from 1970 to 1982 shown together with emigration rate and emigration biomass for 1975 to 1979

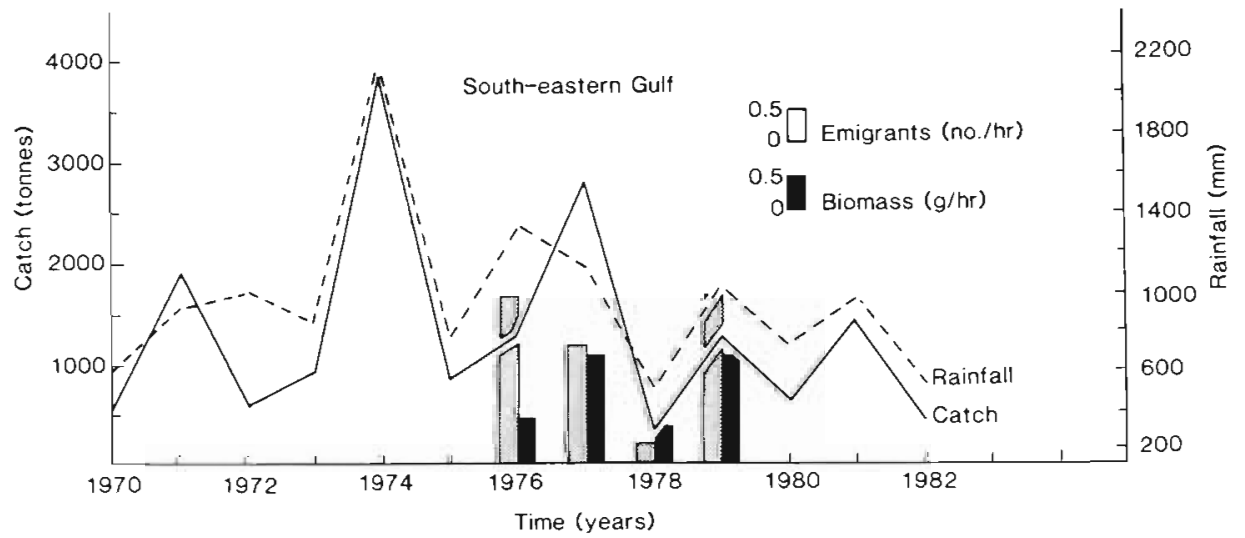


season probably also contributed to this difference. It is clear from the $4 \mathrm{yr}$ of study that the changes in the biomass of emigrating juveniles from the Norman River were reflected in the changes of the commercial catch of the adjacent region.

\section{DISCUSSION}

\section{Migration pathways}

In 3 depth strata near the Norman River estuary mouth, $81 \%$ of the emigrating Penaeus merguiensis juveniles were caught in less than $0.5 \mathrm{~m}$ from the water's surface. Beardsley (1970) found $83 \%$ of $P$. duorarum in the surface waters while they were migrating through a tidal canal in the Gulf of Mexico, Florida. King (1971) reported that $86 \%$ of $P$. aztecus and $88 \%$ of $P$. duorarum caught by set nets were near the surface in a tidal pass in Texas. It appears that emigration near the water surface is a common behaviour pattern among many penaeid prawn species. Similarly, in studies of the lateral distribution of emigrating prawns (e.g. Beardsley 1970, King 1971), the results were similar to those observed in our study, with prawns distributed across the width of the estuary. Small differences can occur during different phases of the tide and moon, but in all cases, samples taken near the surface in the mid-channel position give a good index of both the number and size of emigrating prawns.

In the offshore region adjacent to the river mouth, young Penaeus merguiensis emigrate first to the beach zone near the mouth of the river, but soon migrate offshore as they grow. By comparing the length/frequency changes of adult $P$. merguiensis taken by commercial trawlers in the southeastern Gulf of Carpentaria with the data on emigration of juvenile prawns, it could be established that juvenile prawns took approximately 2 mo to reach the commercial adult population after leaving the estuary. There was a good agreement among the results of sampling emigrating prawns using fixed set nets, sampling adolescent prawns with beam trawls and sampling adult prawns from the commercial fleet. Although it could be argued that changes in the catchability of the set nets with increased current speeds and turbidity could account for many of the results observed during the present study, the agreement among different sampling methods supports the conclusion that set net sampling adequately reflected changes in emigration. By tracing the history of different cohorts of juvenile prawns in the Norman River estuary, Staples (1980) showed that emigrants that left the estuary in the main waves from December to March were from $1 \mathrm{wk}$ to about 3 mo old depending on the timing of the emigration stimuli. The offshore fishery in March and April consists mainly of prawns slightly less than 6 mo old at the time of harvest. During October-November each year, a small number of larger prawns from the small, overwintering juvenile population emigrated from the estuary. In some years, when this group is more abundant, these older prawns may also contribute to the commercial stock. Redfield (pers. comm.) argues that this group becomes mature soon after leaving the estuary and may be an important spawning stock.

\section{Stimulus for migration}

Prawns emigrated in response to increased rainfall. Increased rainfall, however, changes a number of physical and chemical parameters in the estuary, most obviously increasing current speeds, decreasing salinity and temperature and causing associated changes in nutrients and other chemicals (Staples 1983). Hughes (1969) demonstrated experimentally that Penaeus duorarum juveniles placed in a uniform current showed a positive rheotropism when salinity was high (i.e. they swam upstream). Conversely, when salinity decreased, the prawns began to move downstream and were finally carried passively with the current. In the present study, the size of emigrating $P$. merguiensis was inversely related to the number of emigrating prawns over all time scales, with salinity changes being the most important factor affecting their size. Dall (1981) has shown experimentally that larger $P$. merguiensis are less tolerant of low salinity than small $P$. merguiensis. This suggests that when salinity in the estuary is high, only a few of the larger individuals are stimulated to migrate, but that as salinities decrease, more smaller prawns emigrate. Under most environmental conditions, therefore, prawns are not physically flushed out of the estuary with increasing water discharge, but leave selectively in response to changing salinities. This mechanism would allow for changing proportions of the resident population to emigrate at different rainfall levels, so that emigration over larger time scales is largely independent of the number of resident prawns.

As pointed out by Garcia (1977) and Staples (1980). the Hughes (1969) hypothesis concerning different prawn behaviour at different salinities fails to account for the occasions when prawns emigrate against a positive salinity gradient. It also fails to account for emigration increasing after increased rainfall, even though the salinity in the entire estuary remains $<1 \times$ $10^{-3}$ during the whole period (Ruello 1973, Staples 1980). The importance of current speed changes has also been invoked (Garcia 1977); in the present study, 
increased emigration was certainly associated with increased discharge over both tides and seasons. However, during a tidal surge associated with cyclone Ted in December 1976, changes in current speeds alone without changes in salinity or other chemical factors did not elicit emigration of juveniles from the estuary (Staples 1980). More experimental work to study the combined effects of the different factors (including terrestial cues) is required.

\section{Factors affecting emigration}

On short time scales, several factors were found to influence prawn emigration. These included rainfall, number of juvenile prawns in the estuary at the time of migration, and tide phase. Rainfall, summed for the 3 wk prior to sampling, accounted for the largest part of the variation observed in weekly prawn emigration. Several workers have demonstrated that more prawns emigrate during the full and new moon periods, with an apparently larger peak around the time of new moon (e.g. Copeland 1965, Subrahmanyam 1967, Yokel et al. 1969, Garcia 1977). However, most of these studies have been carried out in locations where tidal and lunar phases are synchronous, the spring tides coinciding with full and new moons. The most likely explanation of higher catch rates of emigrants in these locations is that the increased water currents associated with spring tides result in increased water volume filtered by nets. In the southeastern Gulf of Carpentaria, where the changes of the moon phase and tidal phase are not synchronous, we hoped that the lunar and tidal effects could be separated. However, from December to March each year, when most prawn emigration occurred, spring tides were roughly coincidental with new and full moon, with a lag of only 2 to $3 \mathrm{~d}$, throughout the period. This made it difficult to separate the effects of moon phase from tidal height effects, although our analysis showed that emigration rates was more highly correlated with tide height changes than with lunar phase changes. Moon phase effects were not significant after the effects of rainfall, juvenile abundance and tide height had been removed by multiple regression techniques.

Postlarval immigration into the Norman River during flood tide periods was also cyclic, with peaks of postlarvae (both numbers per water volume filtered by the nets and numbers caught per minute) occurring during the spring tide, with a larger peak every second spring tide period (Staples \& Vance 1985). Increased immigration occurred during the fortnight when moon set and low tide coincided and the period of flood tide during the night was not moonlit. In the present study, juvenile migration peaked 1 fortnight out of phase with the peak of postlarval immigration, i.e. during the period when there was no moonlight at ebb tide. Moon phase, per se, may not be important in controlling prawn migration, but there may be a phase relation between the times of moon set and the initiation of either flood or ebb tides.

When the data on the emigration of Penaeus merguiensis were pooled, much of the noise associated with the day-to-day emigration and the effects of tidal and lunar phases could be eliminated and emigration became much more strongly correlated with rainfall. Multiple regression analysis suggested that other factors such as the number and size of resident prawns had little additional effect. Recent simulations, however, have shown that underlying density relations are difficult to detect by multiple regression analyses when environmental effects are large (Goodyear \& Christensen 1984). In some years, when the juvenile population was small, the lack of juveniles did appear to be limiting. It is also obvious that at zero population level, no emigration will occur, regardless of rainfall. We conclude from these results that the best model to relate juvenile numbers to emigration on an annual basis is a series of asymptotic functions passing thorugh the origin such that at low densities of resident prawn populations, emigration is related to both juvenile numbers and rainfall, but at higher densities, rainfall increasingly becomes more important in determining the strength of emigration and subsequent commericial catch.

Acknowledgements. Mr D. Heales of the Division of Fisheries Research, CSIRO Marine Laboratories, Cleveland, assisted greatly in the collection of field data for this study. Access to unpublished data of $\mathrm{Mr}$ I. Somers of the same laboratories is also gratefully acknowledged. Mr John Kerr, Division of Mathematics and Statistics, CSIRO Long Pocket Laboratories, assisted in many of the statistical analyses. The first draft of the paper was read and constructively criticized by Drs $W$ Dall, B. Hill, and P. Rothlisberg of the CSIRO Division of Fisheries Research.

\section{LITERATURE CITED}

Beardsley, G. L. (1970). Distribution of migrating juvenile pink shrimp Penaeus duorarum duorarum Burkenroad, in Buttonwood Canal, Everglades National Park, Florida. Trans. Am. Fish. Soc. 99: 401-408

Boddeke, R., Dijkema, R., Simelink, M. E. (1977). The patterned migration of shrimp populations: a complete study of Crangon crangon and Penaeus schmitti. FAO Fish. Rep. 200: $31-49$

Chatfield, C. (1975). The analysis of time series: theory and practice. John Wiley and Sons, New York

Chong, V. C. (1979). The biology of the white prawn Penaeus merguiensis de Man (Crustacea: Penaeidae) in the Pulau Angsa-Klang Strait waters (Straits of Malacca). M. S. thesis, University of Malaysia, Kuala Lumpur

Copeland, B. J. (1965). Fauna of Aransas Pass Inlet, Texas. 
Part 1. Emigration as shown by tide trap collections. Publ. Inst. Mar. Sci. Univ. Tex. 10: 9-21

Crocos, P. J., Kerr, J. D. (1983). Maturation and spawning of the banana prawn Penaeus merguiensis de Man (Crustacea: Penaeidae) in the Gulf of Carpentaria, Australia. J. exp. mar. Biol. Ecol. 69: 37-59

Dall, W (1981). Osmoregulatory ability and juvenile habitat preference in some penaeid prawns. J. exp. mar, Biol. Ecol. 54: 55-64

Draper, N. R., Smith, N. (1966). Applied regression analyses. Wiley, New York

Garcia, S. (1977). Les migrations des crevettes penaeides tropicales. Oceanis $1977 \cdot 365-380$

Garcia, S., LeReste, L. (1981). Life cycles, dynamics, exploitation and management of coastal penaeid shrimp stocks. FAO Fish. Techn. Pap. 203: 1-215

Goodyear, C. P., Christensen, S. W. (1984). On the ability to detect the influence of spawning stock on recruitment. North Am. J. Fish. Manage. 4: 186-193

Hughes, D. A. (1969). Responses of salinity change as a tidal transport mechanism of pink shrimp Penaeus duorarum. Biol. Bull mar. biol. Lab., Woods Hole 136: 43-53

Hynd, J. S. (1974): Year-round fishery possible in the Gulf? Aust. Fish. 33: 2-5

Idyll, C. P., Iversen, E. S., Yokel, B. (1964). Movements of juvenile pink shrimp in the Everglades National Park, Florida. Proc. Gulf Caribb. Fish. Inst. 16: 51-52

King, B. D. (1971). Study of migratory pattern of fish and shell fish through a natural pass. Tex. Parks. Wildl. Tech. Ser. 9: $1-54$

Munro, I. S. R. (1975). Biology of the banana prawn (Penaeus merguiensis) in the south-east corner of the Gulf of Carpentaria. In: Young, P. C. (ed.) First national prawn seminar. Australian Government Publishing Service, Canberra, p. $60-78$

Racek, A. A. (1959). Prawn investigations in eastern Australia. Res. Bull. State Fish. N. S. W. 6: 1-57
Rothlisberg, P. C., Church, J. A., Forbes, A. M. G. (1983). Advection modelling of vertically migrating shrimp larvae. J. mar. Res. 41: 511-538

Ruello, N. V. (1973). The influence of rainfall on the distribution and abundance of the school prawn Metapenaeus macleayi in the Hunter River region (Australia). Mar. Biol. 23: $221-228$

Staples, D. J (1980). Ecology of juvenile and adolescent banana prawns, Penaeus merguiensis in a mangrove estuary and adjacent offshore area of the Gulf of Carpentaria. II. Emigration, population structure and growth of juveniles. Aust. J. mar. Freshwat. Res. 31: 653-665

Staples, D. J. (1983). Environmental monitoring: climate of Karumba and hydrology of the Norman River estuary, south-east Gulf of Carpentaria. Aust. CSIRO Mar. Lab. Rep. 156: 1-11

Staples, D. J., Vance, D. J. (1985). Short-term and long-term influences on the immigration of postlarval banana prawns Penaeus merguiensis, into a mangrove estuary of the Gulf of Carpentaria, Australia. Mar. Ecol. Prog. Ser. 23: $15-29$

Subrahmanyam, M. (1967). Further observations on the lunar periodicity in relation to the prawn abundance in the Godavari estuarine system. J. mar. biol. Ass. India 9: 111-115

Vance, D. J., Staples, D. J., Kerr, J. D. (1985). Factors affecting year-to-year variation in the catch of banana prawns (Penaeus merguiensis) in the Gulf of Carpentaria, Australia J. Cons. Int. Explor. Mer 42: 83-97

Yokel, B. I., Iversen, E. S., Idyll, C. P. (1969). Prediction of the success of commercial shrimp fishing on the Tortugas grounds, based on enumeration of emigrants from the Everglades National Park estuary. FAO Fish Rep. 57: $1027-1040$ 